\begin{abstract}
CASE
or

TUMOR

IN THE

\section{ANTERIOR MEDIASTINUM,}

contannine

\section{BONE AND TEETH.}

BY JAMES ALEXANDER GORDON, M.D.

PHYSICIAN TO THE ISLINGTON DISPENSARY.

Read Nov. 25th, 1823.

MaRY COOPER, aged 21, a very stout young woman, was admitted a patient of the Islington Dispensary on the 17th of June, 1822, labouring under the usual symptoms of pneumonia. These were in part subdued by copious and repeated blood-letting, but there still remained an irritating cough, and a pulse of 120 which resisted all the usual remedies. The pain of the side occasionally recurred, and was always relieved by blood-letting, but the cough never varied; it was convulsive and suffocating, and was attended with an expectoration, which was at first mucous, and afterwards purulent. The health of the patient had been previously good, 
and it is worthy of remark, that even at this period of the disease, there was no emaciation.

On the 19th of August she pointed out to Dr. John Sims, who was attending for me, a small round tumor, below the sternal extremity of the left clavicle, about the size of a nut, pulsating regularly and strongly. From its appearance and situation, it was pronounced at the consultation which took place on the case, to be an aneurism of the aorta, or of the arteria innominata. The patient was freely bled, put upon spare diet, and the occasional symptoms of irritation relieved by appropriate remedies. In the course of three weeks, the tumor, which rapidly increased, rose above the clavicle, and then somewhat receded. The breathing was always oppressed, though she could inspire without pain or cough; the pulse was uniformly 120 , and the attempt to lie down always excited cough. On the 7 th of November she was removed to St. Bartholomew's Hospital, where she remained till the 9th of December, and was then dismissed for irregularity, and came again to the Dispensary.

The tumor remained for some time stationary. She was regularly bled about once a week, and her health gradually improved, but in the spring of 1823, the tumor which had for, the last four months occupied the same spot, over the sternum, above and between the centre and angle, gradu- 
ally extended over the trachea, occasioning great irritation and threatening suffocation. In the middle of June it began to point on the right side of the sternum, the skin got gradually thinner, and at each pulsation it appeared ready to burst, which it did on the 25th, but nothing but serous fluid flowed. On examining with the probe I found that this was a small superficial sac, occasioned, I presumed, by the pressure of the aneurismal tumor, which at each pulsation pushed the probe out of the sac. No discharge took place after the 1st of August, from which time the tumor gradually receded, and on the 12th of September there was no trace of it. The patient left the Dispensary in better health than she had enjoyed for two years, and went to work.

She again applied on the 17th of October, with symptoms of general fever, and oppressed breathing, but without any local complaint, and she died on the 20th. The body was opened in my presence, on the $22 \mathrm{~d}$, by $\mathrm{Mr}$. Kingdon, one of the surgeons of the institution, the permission to effect which was obtained with great difficulty, and only then under promise of confining the examination to the chest, the fulfilment of which condition was secured by the presence of the father. The following are Mr. K.'s notes of the dissection.

" There was a tumor in the anterior medias. 
tinum, closely attached to the upper two thirds of the sternum, and the sternal extremity of the right clavicle. "The left side of the chest contained a considerable quantity of fluid, and the lung was adherent to all such part of the costal pleura not so occupied. The right lung was adherent on its whole surface, and not capable of being detached at any part; its interior was loaded with fluid, and offered the appearance of œedematous cellular tissue, resembling lung only in its colour. The heart was flaccid, but its interior arrangement apparently healthy. The aorta and vessels given off at its arch were healthy, but the arteria innominata was completely enveloped by the thickened cellular tissue which connected the tumor with the surrounding parts. The parietes of the tumor participated in the character of that with which it was in immediate connexion; thus its anterior, from which the sternum was with difficulty raised, had the close compactness of tendinous expansion; and its posterior and lateral portions were more loose and flaccid. The contents were, serous fluid, sebaceous matter, mixed with hair, the latter not in large quantity nor in distinct locks, and an apparently fatty mass at the bottom, which being cut open proved bony, and on more careful examination, a bone was detected very nearly resembling the upper maxillary, a portion of alveolar process which might seem to belong to the upper or lower maxillary, and seven teeth, two cuspidati, two in- 
cisores, and three molares. One of the cuspidati has its crown perfectly covered with enamel and freed from its capsule; the other is covered with the capsule, but is removed from its socket without any connexion. The molares are in their sockets imperfectly formed, while the incisores are by means of their capsules attached to what at first appeared fat, but which on closer examination seems to possess the character of palatine membrane."

Besides Mr. Highmore's case, published in 1815, and those alluded to in that publication, there are many on record in the Philosophical Transactions*, which may be fairly classed with the one just related, since I should consider the tumor had co-existence with the subject from which it was taken, and was carried without inconvenience, till inflammation in its neighbourhood excited that fluid secretion upon which its enlargement and consequent inconvenience depended.

The preparation is in the possession of Mr. Stanley.

* Case of a male grey-hound passing per anum a mass resembling a whelp.-Vol. XIX.p. 316.

Account of a child born with a tumor near the anus, containing some rudiments of an embryo.-Vol. XLV.p. 325. 